\title{
Türkiye'de ulusal veteriner anatomi kongrelerinde sunulan bildiriler: bir eğilim analizi
}

\author{
Ömer Gürkan DİLEK, Yasin DEMIRASLAN, İftar GÜRBÜZ
}

Burdur Mehmet Akif Ersoy Üniversitesi, Veteriner Fakültesi, Anatomi Anabilim Dalı, Burdur/TÜRKIYE

Anahtar Kelimeler:
bildiri
eğilim
kongre
veteriner anatomi

veteriner anatomi

Key Words:

proceeding

trend

congress

veterinary anatomy

Geliș Tarihi: 25.09.2019

Kabul Tarihi: 31.10.2019

Yayin Tarihi: 31.12.2019

Makale Kodu: 516280

\section{ÖZ}

Bu çalıșma 2000-2015 yılları arasında Türkiye'de yapılan veteriner anatomi kongrelerinde sunulmuş bildirilerin bazı özellikler bakımından eğilimlerini belirlemek amacıyla yapıldı. Calıșmada 2000-2015 yılları arasında Türkiye'de yapılan veteriner anatomi kongrelerinde sunulmuş bildiriler kullanıldı. Bildiriler yıl-sistem, yıl-hayvan türü, cinsiyet-sistem, cinsiyet-hayvan türü şeklinde sınıflandırıldı. Verilerin frekans (f) ve yüzde (\%) değerleri Microsoft Excel 2010 programında hesaplandı. Çalıșmada y1l-sisteme göre yapılan sınıflandırmada en çok bildirinin (f: 65, \% 14.7) 2015' de yayınlandığ1 görüldü. Aynı sinıflandırmada en çok bildirinin hareket sistemine (f: 89, \% 20.1) ait olduğu belirlendi. Yıl-hayvan türüne göre yapılan değerlendirmede bildirilerde en çok köpeğin (f: 62 , \% 12.35) kullanıldığ1 görüldü. Cinsiyet-sisteme göre yapılan analizde kadın ve erkek araştırmacıların en çok hareket sistemi ile ilgili araștırma konularına(kadın; f: 24, \% 24, erkek; f: $65, \%$ 18.90) yöneldiği tespit edildi. Cinsiyet hayvan türüne göre yapılan analizde kadın ve erkek araştırmacıların bildirilerinde en çok köpeği (kadın; f: 15, \% 12.82, erkek; f: 47, \% 12.24) kullandıkları saptandı. Sonuç olarak Türkiye'de veteriner anatomi alanında düzenlenmiş ulusal kongrelerde sunulan bildiriler bazı özellikler bakımından değerlendirilerek, yönelimler belirlenmeye çalışılmıştır.

\section{Researches which presented at national veterinary anatomy congresses in Turkey: a trend analysis}

\section{Sorumlu Yazar: ÖG. DILEK \\ (ogdilek@gmail.com)}

ORCİD:

ÖG. DILEK: 0000-0002-5717-3928 Y. DEMIRASLAN: 0000-0003-3612-6142

İ. GÜRBÜZ: 0000-0001-9460-0645

\begin{abstract}
This study was conducted in order to determine the trends of presented researches in the field of Veterinary Anatomy Congresses in Turkey between 2000 and 2015 at terms of certain qualification. In the study, congress proceedings were presented in the veterinary anatomy congresses held between 2000 and 2015 in Turkey. Congress proceedings were classified according to year-system, year-animal species, gender-system, gender-animal species. Frequency and percentage values of data were calculated by using Microsoft Excel 2010 programme. In the year-system classification of the study most of proceedings ( $\mathrm{f}: 65, \%$ 14.7) were found to be published in 2015. In the same classification, most of proceedings were belong to locomotor system (f: $89, \%$ 20.1). In the evaluation conducted according to year-animal species, dog was found to be most commonly used in scientific studies. In the gender-system analysis, women and men mostly preferred the motion system on the proceedings (woman; f: 24 , $\%$ 24, men; f: 65, \% 18.90). In the gender-animal species analysis, women and men mostly research on dogs (woman; f: 15, \% 12.82, men; f: 47, \% 12.24). As a result, the reports presented in the national congresses that organized veterinary anatomy in Turkey were evaluated in terms of some features and tried to determine the orientations.
\end{abstract}

\section{GİRİ̧}

Veteriner anatomi, veteriner cerrahların eğitim uygulamalarında sıklıkla başvurdukları bir anabilim dalıdır. Bu alanda gelişen teknoloji, anatomi eğitiminde ve anatomik araştırmalarda da kullanılmaktadır (1). Türkiye'de veteriner anatomi çalıșmalarında teknolojik gelişmelerden yararlanarak belirli bir eğilimin yön verip vermediği bilinmemektedir.
Akademik disiplinlerde üretilen yeni fikirler bilimsel makaleler aracıllŏıyla paylaşılmaktadır. Bu nedenle bilgi üretilir ve akademik iletişim etkinleştirilir. Akademisyenler doğru ve güvenilir bilgi üretmek için çalışan bilim insanlarıdır (2). Staton-Spicer ve Wulf (3), bir disiplinin çalışma alanını belirlemede en kabul edilebilir yolun, bu disiplin üzerinde yapılan çalışmaların değerlendirilmesi olduğunu bildirmiştir. Cohen ve ark. (4) belirli bir disiplin üzerinde yapılan çalıșmaların incelenmesinin, bu disiplin üzerinde çalışma yapmak isteyenlere gösterebileceğini 
ortaya koymuştur. Bununla birlikte bilimsel araştırma sonuçlarının sentezi, daha sonraki bilimsel araştırmaların politikalarına ve uygulamalarına yön verdiği bildirilmiştir (2).

'Türkiye' de bilimsel araştırma trendlerini belirlemeye yönelik farklı alanlarla ilgili çok sayıda çalışma yapılmıştır (5-12). Ancak veteriner anatomi alanında kongrelerde sunulan bildirilerin değerlendirildiği herhangi bir çalışmaya rastlanılmamıştır. Bu çalışma 2000-2015 yılları arasında Türkiye'de yapılan veteriner anatomi kongrelerinde sunulmuş bildirilerin bazı özellikler bakımından eğilimlerinin belirlenmesini amaçlamıştır.

\section{GEREÇ ve YÖNTEM}

Çalışmada 2000-2015 yılları arasında Türkiye'de yapılan ulusal veteriner anatomi kongrelerinde sunulmuş bildiriler kullanıld1. Bildiriler y1l-sistem, y1l-hayvan türü, cinsiyetsistem, cinsiyet-hayvan türü şeklinde sinıflandırıldı. Yıl-sistem gruplandırılmasında 442 bildiri, yıl-hayvan türüne göre 502, cinsiyet-sisteme göre 444, cinsiyet-hayvan türüne göre ise 501 adet bildiri değerlendirildi. Verilerin frekans (f) ve yüzde (\%) değerleri Microsoft Excel 2010 programında hesaplandi.

\section{BULGULAR}

Tablo 1-4' de çalışmada elde edilen bulgular sunuldu. Y1l-sistem gruplandirılmasina göre en çok bildirinin (f: 65, \% 14.7) 2015 de yayınlandığ1 görüldü. Aynı sınıflandırmada en çok bildirinin hareket sistemine (f: 89, \% 20.1) ait olduğu belirlendi. Y1l-hayvan türüne göre yapılan değerlendirmede bildirilerde en çok köpeğin (f: 62, \% 12.35) kullanıldığ1 görüldü. Cinsiyet-sisteme göre yapılan analizde kadın ve erkek araştırmacıla- rın en çok hareket sistemi ile ilgili araştırma konularına (kadın; f: $24, \%$ 24, erkek; f: $65, \%$ 18.90) yöneldiği tespit edildi. Cinsiyet-hayvan türüne göre yapılan analizde kadın ve erkek araştırmacıların bildirilerinde en çok köpeği (kadın; f: 15, \% 12.82, erkek; f: 47, \% 12.24) kullandıkları saptand1.

\section{TARTIŞMA}

Bu çalışmada çeşitli özellikler açısından bildirilerin sınıflandırılması, belirli yorumlara ulaşmak amacıyla araştırılmıştır. Bununla birlikte, literatürde elde edilen kongre bildiri sonuçlar1nın karşılaştırılabileceği insan anatomisi veya veteriner anatomi bildirilerine rastlanılmamıştır. Ancak, Demiraslan ve ark. (7) Türkiye'de veteriner anatomi alanında çalışan bilim insanlarının 1994-2013 yılları arasında bilimsel dergilerde yayımladığ1 makalelerin analizini yapmıştır.

Bu çalışma 'Türkiye' de düzenlenen veteriner anatomi kongre bildirilerinin değerlendirildiği ilk çalışma olmasının yanı sıra, çalışmanın belirli bir zaman aralığını kapsayarak sınırlandırılması bakımından önem taşımaktadır.

Bildiriler, y1l-sistem kriterine göre değerlendirildiğinde en fazla bildirinin 2015 (\% 14.7) y1lındaki ulusal veteriner anatomi kongresinde sunulduğu görülmekle birlikte sirasıyla hareket $(\%$ 20.1), dolaşım (\% 17) ve sinir sistemleri (\% 15.8) anatomistler tarafindan en çok çalışılan sistemler olduğu anlaşılmaktadır. Demiraslan ve ark. (7) ise bilimsel makalelerde Türkiye'de görev yapan veteriner anatomistlerin yayınlarının sirasiyla dolaşım ( $\%$ 27.88), hareket ( $\% 26.57)$, ve sinir (\% 12.85) sistemlerinde olduğunu bildirmiştir. Aynı çalışmada Demiraslan ve ark (7) 1994 ile 2013 y1lları arasında yayımlanan makaleleri incelemiştir. Bu oransal farklılı̆̆ın, bildirilerin makale olarak farklı

Tablo 1 Bildirilerin yıl-sistem sınıflandırılmasına göre değerlendirilmesi.

\begin{tabular}{|c|c|c|c|c|c|c|c|c|c|c|c|}
\hline Sistemler & 2000 & 2002 & 2004 & 2006 & 2008 & 2010 & 2011 & 2013 & 2015 & Toplam & Yüzde \\
\hline Hareket & 17 & 13 & 4 & 9 & 8 & 8 & 10 & 9 & 11 & 89 & 20,1 \\
\hline Sindirim & 6 & 3 & 2 & 5 & 4 & 3 & 2 & 3 & 6 & 34 & 7,7 \\
\hline Solunum & 2 & 3 & 2 & 0 & 2 & 1 & 2 & 4 & 5 & 21 & 4,8 \\
\hline Dolaşım & 7 & 14 & 13 & 10 & 9 & 1 & 9 & 7 & 5 & 75 & 17,0 \\
\hline Boşaltım & 3 & 1 & 1 & 1 & 2 & 0 & 4 & 2 & 1 & 15 & 3,4 \\
\hline Genital & 6 & 2 & 2 & 1 & 2 & 0 & 2 & 1 & 3 & 19 & 4,3 \\
\hline Sinir & 7 & 8 & 8 & 4 & 5 & 7 & 5 & 12 & 14 & 70 & 15,8 \\
\hline Endokrin & 5 & 2 & 1 & 2 & 2 & 1 & 4 & 1 & 5 & 23 & 5,2 \\
\hline Eğitim & 1 & 2 & 0 & 0 & 7 & 7 & 1 & 8 & 12 & 38 & 8,6 \\
\hline Duyu & 3 & 1 & 2 & 2 & 1 & 0 & 1 & 1 & 2 & 13 & 2,9 \\
\hline Diğer & 6 & 3 & 2 & 4 & 5 & 4 & 13 & 7 & 1 & 45 & 10,2 \\
\hline Toplam & 63 & 52 & 37 & 38 & 47 & 32 & 53 & 55 & 65 & 442 & \\
\hline Yüzde & 14,3 & 11,8 & 8,4 & 8,6 & 10,6 & 7,2 & 12,0 & 12,4 & 14,7 & 884 & 100,0 \\
\hline
\end{tabular}


Tablo 2 Bildirilerin yıl-hayvan türü sınıflandırılmasına göre değerlendirilmesi.

\begin{tabular}{|c|c|c|c|c|c|c|c|c|c|c|c|c|}
\hline Türler & & 2000 & 2002 & 2004 & 2006 & 2008 & 2010 & 2011 & 2013 & 2015 & Toplam & Yüzde \\
\hline \multirow{2}{*}{ Equidae } & At & 6 & 6 & 0 & 0 & 1 & 3 & 10 & 5 & 6 & 37 & 7,37 \\
\hline & Merkep & 0 & 1 & 3 & 2 & 3 & 0 & 0 & 2 & 0 & 11 & 2,19 \\
\hline \multirow{8}{*}{ Ruminant } & Sığır & 5 & 6 & 7 & 5 & 3 & 2 & 6 & 6 & 3 & 43 & 8,57 \\
\hline & Manda & 0 & 3 & 2 & 0 & 0 & 0 & 0 & 0 & 0 & 5 & 1,00 \\
\hline & Bufalo & 0 & 0 & 0 & 0 & 2 & 0 & 0 & 0 & 0 & 2 & 0,40 \\
\hline & Karaca & 0 & 0 & 0 & 0 & 0 & 1 & 1 & 1 & 0 & 3 & 0,60 \\
\hline & Ceylan & 0 & 0 & 2 & 0 & 0 & 0 & 0 & 0 & 2 & 4 & 0,80 \\
\hline & Koyun & 5 & 8 & 2 & 7 & 1 & 2 & 3 & 8 & 3 & 39 & 7,77 \\
\hline & Keçi & 3 & 4 & 2 & 3 & 2 & 3 & 3 & 5 & 3 & 28 & 5,58 \\
\hline & Deve & 0 & 0 & 1 & 0 & 0 & 0 & 0 & 0 & 0 & 1 & 0,20 \\
\hline \multirow{10}{*}{ Carnivora } & Köpek & 11 & 11 & 7 & 7 & 3 & 3 & 8 & 7 & 5 & 62 & 12,35 \\
\hline & Sansar & 0 & 1 & 0 & 0 & 0 & 0 & 0 & 0 & 2 & 3 & 0,60 \\
\hline & Vaşak & 0 & 0 & 0 & 0 & 0 & 0 & 0 & 0 & 1 & 1 & 0,20 \\
\hline & Su Samuru & 3 & 0 & 0 & 0 & 0 & 0 & 0 & 0 & 0 & 3 & 0,60 \\
\hline & Kirpi & 1 & 2 & 4 & 1 & 0 & 2 & 0 & 2 & 0 & 12 & 2,39 \\
\hline & Porsuk & 1 & 0 & 0 & 0 & 0 & 0 & 0 & 0 & 0 & 1 & 0,20 \\
\hline & Kurt & 0 & 0 & 0 & 0 & 0 & 0 & 0 & 0 & 1 & 1 & 0,20 \\
\hline & Tilki & 0 & 0 & 0 & 0 & 0 & 0 & 1 & 0 & 0 & 1 & 0,20 \\
\hline & Aslan & 1 & 0 & 0 & 0 & 0 & 0 & 0 & 0 & 0 & 1 & 0,20 \\
\hline & Kedi & 9 & 10 & 3 & 3 & 1 & 1 & 1 & 3 & 2 & 33 & 6,57 \\
\hline \multirow{8}{*}{$\begin{array}{l}\text { Laboratuvar } \\
\text { Hayvanları }\end{array}$} & Tavşan & 8 & 4 & 1 & 7 & 6 & 3 & 5 & 4 & 1 & 39 & 7,77 \\
\hline & Rat & 2 & 0 & 2 & 1 & 5 & 1 & 3 & 3 & 1 & 18 & 3,59 \\
\hline & Şinşilla & 0 & 0 & 0 & 2 & 1 & 0 & 0 & 0 & 1 & 4 & 0,80 \\
\hline & Sincap & 0 & 2 & 1 & 2 & 1 & 1 & 2 & 0 & 0 & 9 & 1,79 \\
\hline & Guina pig & 1 & 0 & 0 & 0 & 0 & 0 & 0 & 0 & 0 & 1 & 0,20 \\
\hline & Kobay & 1 & 5 & 0 & 0 & 0 & 0 & 1 & 0 & 0 & 7 & 1,39 \\
\hline & Siçan & 0 & 0 & 0 & 0 & 0 & 0 & 2 & 0 & 0 & 2 & 0,40 \\
\hline & Fare & 2 & 1 & 1 & 3 & 1 & 1 & 2 & 5 & 2 & 18 & 3,59 \\
\hline \multirow{17}{*}{ Aves } & Tavuk-Horoz & 6 & 3 & 2 & 5 & 1 & 3 & 2 & 4 & 3 & 29 & 5,78 \\
\hline & $\mathrm{Kaz}$ & 2 & 1 & 1 & 0 & 0 & 0 & 1 & 0 & 1 & 6 & 1,20 \\
\hline & Ördek & 3 & 1 & 0 & 0 & 1 & 0 & 1 & 1 & 1 & 8 & 1,59 \\
\hline & Flamingo & 0 & 0 & 0 & 0 & 0 & 0 & 0 & 0 & 1 & 1 & 0,20 \\
\hline & Bildırcin & 2 & 0 & 0 & 1 & 1 & 1 & 1 & 1 & 3 & 10 & 1,99 \\
\hline & $\begin{array}{c}\text { Muhabbet } \\
\text { kuşu }\end{array}$ & 1 & 1 & 0 & 0 & 0 & 0 & 0 & 0 & 0 & 2 & 0,40 \\
\hline & Balıkçıl kuş & 0 & 0 & 0 & 0 & 1 & 0 & 0 & 0 & 1 & 2 & 0,40 \\
\hline & Baykuş & 0 & 0 & 0 & 0 & 1 & 0 & 0 & 0 & 0 & 1 & 0,20 \\
\hline & Atmaca & 0 & 0 & 0 & 0 & 0 & 0 & 1 & 3 & 1 & 5 & 1,00 \\
\hline & Şahin & 0 & 0 & 1 & 1 & 1 & 1 & 0 & 1 & 4 & 9 & 1,79 \\
\hline & Deve Kuşu & 0 & 1 & 0 & 0 & 0 & 0 & 1 & 0 & 0 & 2 & 0,40 \\
\hline & Hindi & 2 & 0 & 0 & 1 & 5 & 0 & 0 & 0 & 1 & 9 & 1,79 \\
\hline & Keklik & 0 & 0 & 0 & 0 & 0 & 1 & 3 & 0 & 0 & 4 & 0,80 \\
\hline & Leylek & 0 & 0 & 0 & 0 & 0 & 0 & 0 & 1 & 0 & 1 & 0,20 \\
\hline & Saksağan & 0 & 0 & 0 & 0 & 0 & 0 & 0 & 0 & 4 & 4 & 0,80 \\
\hline & Güvercin & 3 & 0 & 1 & 0 & 0 & 0 & 0 & 1 & 0 & 5 & 1,00 \\
\hline & Sülün & 0 & 0 & 0 & 0 & 0 & 1 & 1 & 0 & 0 & 2 & 0,40 \\
\hline \multirow{2}{*}{ Sus } & Evcil & 0 & 0 & 1 & 0 & 0 & 0 & 0 & 0 & 0 & 1 & 0,20 \\
\hline & Yabani & 0 & 0 & 0 & 0 & 0 & 0 & 3 & 2 & 3 & 8 & 1,59 \\
\hline \multirow{2}{*}{ Balık } & Yunus & 0 & 0 & 0 & 2 & 0 & 0 & 1 & 0 & 0 & 3 & 0,60 \\
\hline & Sazan balığ1 & 0 & 0 & 0 & 0 & 0 & 0 & 1 & 0 & 0 & 1 & 0,20 \\
\hline Toplam & & & & & & & & & & & 502 & 100,00 \\
\hline
\end{tabular}


Tablo 3. Bildirilerin cinsiyet-sistem sinıflandırılmasına göre değerlendirilmesi

\begin{tabular}{c|ccccc|}
\hline \multicolumn{5}{c}{ Cinsiyet } \\
\hline Sistemler & Kadın & Kadın Yüzde & Erkek & $\begin{array}{c}\text { Erkek } \\
\text { Yüzde }\end{array}$ \\
\hline $\begin{array}{c}\text { Hareket } \\
\text { Sindirim }\end{array}$ & 24 & 24,00 & 65 & 18,90 \\
\hline Solunum & 5 & 4,00 & 26 & 7,56 \\
\hline Dolaşım & 17 & 5,00 & 18 & 5,23 \\
\hline Boşaltım & 3 & 17,00 & 58 & 16,86 \\
\hline Genital & 7 & 3,00 & 16 & 4,65 \\
\hline Eğitim & 1 & 7,00 & 13 & 3,78 \\
\hline Sinir & 17 & 1,00 & 37 & 10,76 \\
\hline Endokrin & 9 & 17,00 & 53 & 15,41 \\
\hline Duyu & 0 & 9,00 & 14 & 4,07 \\
\hline Diğer & 13 & 0,00 & 13 & 3,78 \\
\hline Toplam & 100 & 13,00 & 31 & 9,01 \\
\hline
\end{tabular}

zamanlarda yayımlanması veya her iki çalışmanın farklı zaman dilimlerini ele almasından kaynaklanabileceği düşünülmektedir.

Y1l-hayvan türlerine göre bildirilerin değerlendirilmesinde, en çok çalışılan hayvan grubunun ruminant'lar olduğu saptanmiştır. (Tablo 2, f: 125, \% 24.92). En çok çalışılan üç hayvan türünün ise köpek (f: 62, \% 12.35), sığır (f: 43,\% 8.57), tavşan (f: $39, \%$ 7.77) ve koyun (f: $39 \%$ 7.7) olduğu belirlenmiştir. Bu veriler ruminant çalışma materyallerinin mezbaha kaynaklı olduğu düşünüldüğünde, araştırmacıların temini daha kolay olan hayvanları kullandığ1 sonucunu düşündürmektedir.

Sistem-cinsiyete göre yürütülen makalelerin sınıflandırılmasinda; kadınlar ve erkeklerin en fazla hareket sistemi üzerinde (\% 24, \% 18.90) çalıştıkları sonucuna ulaşıldı. Bu sonucun hareket sistemini oluşturan (özellikle iskelet-kemik) yapıların kullanıldığı çalışmalarda bulgu alımı aşamasına daha hızlı geçilmesinden kaynaklanabileceği düşünülmektedir.

Sonuç olarak bu çalışmada 2000-2015 yılların arasında düzenlenmiş olan veteriner anatomi kongrelerinde sunulmuş olan bildiriler belirli kriterler dahilinde incelenmiştir. Bulgulara dayalı olarak araştırmacıların eğilimleri tespit edilmiştir. Bu çalışmanın bulgularının önümüzdeki yıllar için bir arşiv verisi oluşturacağı ve genç araştırmacıların çalışmaları ile yönelimlerine 1ş1k tutacağı kanaatindeyiz. 
Tablo 4. Bildirilerin cinsiyet-hayvan türüne sınıflandırılmasına göre değerlendirilmesi.

\begin{tabular}{|c|c|c|c|c|c|}
\hline \multirow[b]{3}{*}{ Familya } & \multirow[b]{3}{*}{ Tür } & \\
\hline & & & & & \\
\hline & & Kadın & Kadın Yüzde & Erkek & Erkek Yüzde \\
\hline \multirow{2}{*}{ Equidae } & At & 8 & 6,84 & 29 & 7,55 \\
\hline & Merkep & 2 & 1,71 & 9 & 2,34 \\
\hline \multirow{8}{*}{ Ruminant } & Sığır & 10 & 8,55 & 33 & 8,59 \\
\hline & Ceylan & 1 & 0,85 & 3 & 0,78 \\
\hline & Manda & 0 & 0,00 & 5 & 1,30 \\
\hline & Bufalo & 0 & 0,00 & 2 & 0,52 \\
\hline & Karaca & 2 & 1,71 & 1 & 0,26 \\
\hline & Koyun & 8 & 6,84 & 31 & 8,07 \\
\hline & Keçi & 7 & 5,98 & 21 & 5,47 \\
\hline & Deve & 0 & 0,00 & 1 & 0,26 \\
\hline \multirow{18}{*}{ Laboratuvar Hayvanları } & Kirpi & 3 & 2,56 & 9 & 2,34 \\
\hline & Su samuru & 0 & 0,00 & 3 & 0,78 \\
\hline & Kurt & 0 & 0,00 & 1 & 0,26 \\
\hline & Vaşak & 0 & 0,00 & 1 & 0,26 \\
\hline & Porsuk & 0 & 0,00 & 1 & 0,26 \\
\hline & Aslan & 1 & 0,85 & 0 & 0,00 \\
\hline & Sansar & 0 & 0,00 & 3 & 0,78 \\
\hline & Tilki & 0 & 0,00 & 1 & 0,26 \\
\hline & Köpek & 15 & 12,82 & 47 & 12,24 \\
\hline & Kedi & 5 & 4,27 & 28 & 7,29 \\
\hline & Tavşan & 11 & 9,40 & 28 & 7,29 \\
\hline & Sincap & 0 & 0,00 & 9 & 2,34 \\
\hline & Şinşilla & 1 & 0,85 & 3 & 0,78 \\
\hline & Rat & 5 & 4,27 & 13 & 3,39 \\
\hline & Guina pig & 1 & 0,85 & 0 & 0,00 \\
\hline & Kobay & 1 & 0,85 & 6 & 1,56 \\
\hline & Siçan & 1 & 0,85 & 1 & 0,26 \\
\hline & Fare & 3 & 2,56 & 15 & 3,91 \\
\hline \multirow{17}{*}{ Aves } & Tavuk-Horoz & 5 & 4,27 & 24 & 6,25 \\
\hline & $\mathrm{Kaz}$ & 3 & 2,56 & 3 & 0,78 \\
\hline & Ördek & 2 & 1,71 & 6 & 1,56 \\
\hline & Baykuş & 1 & 0,85 & 0 & 0,00 \\
\hline & Muhabbet kuşu & 0 & 0,00 & 2 & 0,52 \\
\hline & Bildırcin & 5 & 4,27 & 5 & 1,30 \\
\hline & Balıkçıl kuş & 2 & 1,71 & 0 & 0,00 \\
\hline & Deve Kuşu & 0 & 0,00 & 2 & 0,52 \\
\hline & Flamingo & 0 & 0,00 & 1 & 0,26 \\
\hline & Saksağan & 1 & 0,85 & 3 & 0,78 \\
\hline & Leylek & 0 & 0,00 & 1 & 0,26 \\
\hline & Şahin & 2 & 1,71 & 7 & 1,82 \\
\hline & Atmaca & 2 & 1,71 & 3 & 0,78 \\
\hline & Hindi & 3 & 2,56 & 6 & 1,56 \\
\hline & Keklik & 0 & 0,00 & 3 & 0,78 \\
\hline & Güvercin & 2 & 1,71 & 3 & 0,78 \\
\hline & Sülün & 0 & 0,00 & 2 & 0,52 \\
\hline \multirow{2}{*}{ Sus } & Evcil & 0 & 0,00 & 1 & 0,26 \\
\hline & Yabani & 4 & 3,42 & 4 & 1,04 \\
\hline \multirow{2}{*}{ Balık } & Yunus & 0 & 0,00 & 3 & 0,78 \\
\hline & Sazan Balığ1 & 0 & 0,00 & 1 & 0,26 \\
\hline Toplam & & 117 & & 384 & \\
\hline
\end{tabular}




\section{KAYNAKLAR}

1. Salazar I. Coming Changes in Veterinary Anatomy: What Is or Should Be Expected? JVME 2002;29: 126-130.

2. Ozan C, Kose E. Eğitim Programları ve Öğretim Alanındaki Araştırma Eğilimleri. SUJE. 2014; 4: 116-136.

3. Staton-Spicer AQ, Wulff DH. Research in Communication and Instruction: Categorization and Synthesis. Communicative Education 1984; 33: 377-391.

4. Cohen L, Manion L, Morrison K. Research methods in education (6th ed.). Routledge, New York, 2007.

5. Apaydin S. 2000-2008 Y1lları Arasında Türkiye`de Fizik Eğitimi Araştırmaları. I. Uluslararası Türkiye Eğitim Araştırmaları Kongresi, Çanakkale Onsekiz Mart Üniversitesi, Antalya, 2009.

6. Aydın A, Uysal S. Türkiye'de ve Yurt Dışında Eğitim Yönetimi Alanında Yapılan Doktora Tezlerinin Konu, Yöntem ve Sonuçlar Açısından Değerlendirilmesi. EJER 2011, 42: 1-14.

7. Demiraslan Y, Aykut M, Gürbüz I, Özgel Ö. Research and Analysis in the Field of Veterinary Anatomy Between 1994 and 2013 in Turkey. Kocatepe Vet J. 2016; 9(1): 1-11.

8. Erdem D. Türkiye'de 2005-2006 Yillar1 Arasında Yayımlanan Eğitim Bilimleri Dergilerindeki Makalelerin Bazı Özellikler Açısından İncelenmesi: Betimsel Bir Analiz. Eğitimde ve Psikolojide Ölçme ve Değerlendirme Dergisi 2011; 2: 140-147.

9. Goktas Y, Hasancebi F, Varisoglu B, Akcay A, Bayrak N, Baran M, Sozbilir M. Trends in Educational Research in Turkey: A Content Analysis. Educational Sciences: Theory\&Practice 2012; 12: 455-460.

10. Incekara S. Uluslararası Alanda Coğrafya Eğitimi Araştırmaları ve Türkiye'den Örnekler: Mevcut Durum ve Gelecek Yönler. Doğu Coğrafya Dergisi 2009; 21: 123-136.

11. Seçer İ, Ay I, Ozan C, Yılmaz BY. Rehberlik ve Psikolojik Danışma Alanındaki Araştırma Eğilimleri: Bir İçerik Analizi. Turkish Phsyhological Counseling and Guidance Journal 2014; 5(41): 49-60.

12. Sozbilir M, Kutu H. Development and Current Status of Science Education Research in Turkey. Essays in Education [Special issue] 2008; 1-22. 